\title{
The entry of logistics service provider (LSP) into the wine industry supply chain
}

\author{
François Fulconis ${ }^{1}$, Didier Bédé ${ }^{2}$, Laurence Saglietto $^{3}$, Joice de Almeira Goes ${ }^{3}$, Gilles Paché ${ }^{4}$, and Raymundo Forradelas ${ }^{5}$ \\ ${ }^{1}$ University of Avignon \& Aix-Marseille University, CRET-LOG, Avignon, France \\ ${ }^{2}$ University of Toulouse III, LGCO, Toulouse, France \\ ${ }^{3}$ University of Nice Sophia-Antipolis, GREDEG CNRS, Nice, France \\ ${ }^{4}$ Aix-Marseille University, CRET-LOG, Aix-en-Provence, France \\ ${ }^{5}$ Universidad Nacional de Cuyo, Mendoza, Argentina
}

\begin{abstract}
The purpose of this paper is to study the wine industry supply chain (WSC) organization from a social network approach, with an emphasis on the role of logistics service providers (LSP) could hold in the flow monitoring. We try to understand if LSP can be a substitute to traditional actors for intermediation management. This substitution phenomenon must take account of the wine industry culture that may constitute an obstruction or an accelerator for the development of this activity. We present a conceptual model of the WSC, and we discuss the possible future role of the LSP. This paper introduces a framework contributing to understand worldwide WSC organization, mapping tools and strategies to assess the reasons of their evolution. The cultural impact is underlined in this type of industry showing it could present a boundary to market access for LSP.
\end{abstract}

\section{Introduction}

To understand the complexity of international wine trade, several approaches are possible: for instance, a geographical approach (regarding the evolution of production and consumption areas directly related to export flows), or an economic approach (since the 1960s, the production is increasing and its structure has changed with the emergence of new markets). The stakes are high, given the profits generated by this industry. Mariani et al. [1] explore the changes that occurred in the geography of international trade. The aggregated wine import flows were divided into five groups of countries according to their role in the international market: major importers (Germany, the UK and USA, the three countries which have long been the main export destinations for wine), small traditional importers (12 countries), small non-traditional importers (56 countries), major Mediterranean exporting countries (France, Greece, Italy, Spain, Portugal), and other exporters (New-Zealand, Australia, Argentina, Chile, South Africa).

Mediterranean exporting countries have lost market share in favor of other exporting countries that have increased their market share. This is partly due to the preferences of many consumers for imported wines as well as on the transfer of production from small units to multinational groups. Thus, the international distribution network has changed to fit to the new international structure of demand. A recent phenomenon has emerged: intermediation. Intermediation has developed in countries other than the consumer and producer ones (e.g. Singapore for example). Henceforth, the traditional com- petitive relationships among intermediaries and vertical relationships in the supply chain have been changed. Today, the number of intermediaries has increased, be it market-makers or match-makers. Mariani et al. [1] show clearly the phenomenon of re-export through intermediaries, as following: "by combining statistics on wine production and exports it is possible to identify some exporting countries without domestic production or with a production lower than their exports. By filtering wine exporters in the way a set of 33 re-exporting countries was identified".

Beside these geographical or economic approaches, more territorial [2] and managerial approaches [3] focus on the performance of the wine industry supply chain (WSC). It became an important issue for many parts of both the old and new world. Indeed, the international wine trade is based on a complex industry insofar as the wine is produced according to specific quality standards (in different regions) and, for being exported requires specific conditions. WSC is complex for several reasons:

- The nature of the product (wine is available in red, rosé, white, sweet and effervescent),

- The large number of heterogeneous actors (they belong to different professional categories: grower, producer, transporter, distributor, retailer, cellar, etc.),

- The relationships between the actors are complex (e.g. the existence of a multi-level system for the distribution cycle that differs depending on the country),

- The requirements of the end consumers are contextualized and cultural, continued pressure from local and

This is an Open Access article distributed under the terms of the Creative Commons Attribution License 4.0, which permits unrestricted use, distribution, and reproduction in any medium, provided the original work is properly cited. 
international competitors intensifies competition on the planet,

- Finally, the legal constraints of the production and distribution make the task even more difficult.

Thus, mapping the WSC is a complex exercise. According to Garcia [4], the dynamics of WSC, "is very complex not only due to quantity of actors who participates to fulfill the customer's requirement, but also because the supply chain integration, which is different according to the culture, agricultural and industrial practices of each country". As any extended logistic chain, it requires " a synchronization of all activities" [5], the information sharing through cooperation in the ultimate aim of creating value for all actors. Appreciating the timing and all physical and information flows of the WSC requires a modeling of flow, relationships, links and actors: "in order to understand the WSC it is necessary to count with a model that represents its operations, its relationships and its dynamics" [4].

We propose to model the heterogeneous actor's network of WSC. The question is whether the logistics service providers (LSP) that have experienced a tremendous growth in Europe, in North America, and in Asia on numerous value chains (agro-industries, automotive industries, convenience goods industries, etc.) could hold the required skills, the expertise but also the organizational culture to extend these assets in the WSC. To achieve this goal, we first discuss the modeling of the supply chain through a generic approach (part 2). In order to appreciate the structure of the WSC, three different levels are considered: the triads, the groups and the complete network (part 3). Then, we examine the capacity of the conventional LSP to penetrate the WSC by looking at the cultural barriers to overcome (part 4). Eventually, we conclude on the importance of three thematic about LSP (part 5). This paper highlights a research program contributing to a better understanding of the WSC, mapping tools and information to assess the reasons for their strength or weakness. We specifically offer insights into the pre-requisite conditions for a thorough analysis of performance criteria and possible improvements in the WSC thanks to the availability of LSP.

\section{Modeling the supply chain}

Mapping the supply chain of a sector or a business has now become an essential tool for analyzing the performance and reducing costs, while creating financial value. This need for modeling, responds to the vertical disintegration that has led firms towards a new organization that link in a network of supply chains. Based on this observation, research in supply chain showed interest in the design of supply chain and the development of supply chain management instruments. There are several definitions of supply chain and supply chain management, highlighting the diversity of models. For example, on one hand, Stevenson [6] defines the supply chain "as a sequence of supplier warehouses, operations, and retail outlets". He differentiates between two kinds of supply chains one relating to goods and the second relating to services and on another hand the Supply Chain Council [7] defines the supply chain as follows: "The supply chain encompasses every effort involved in producing and delivering a final product, from the supplier's supplier to the customer's customer".

Similarly, the SCM has several definitions. According to Handfield \& Nichols [8], "the SCM includes managing information systems involved in sourcing and procurement, production, scheduling, order processing, inventory management, warehousing, distribution and customer service", and according to Chen \& Paulraj [9], "the term of SCM has been used to explain the planning and control of materials and information flows as well as the logistics activities not only internally within a company but also externally between companies". To return to supply chain, its boundaries lie at the heart of the debate, since there are several types of supply chain. In this regard, Chen \& Paulraj [9] analyzed and synthesized over 400 articles from diverse disciplines. They deduced from the results of their study, several key points: "The entire domain of the concept (supply chain) is very extensive and cannot be covered in just one study (hellip). While studies in organizational structure in general have not been lacking, research addressing the network structure conducive to supply chain performance has been very limited" [9]. In this context, supply chain is represented as a linear approach (purchasing-production-distributionend consumption).

Aware of the limitations presented by these initial definitions, Caddy \& Helou [10,11] apply the principles of the Von Bertalanffy's general systems theory [12] to the supply chain and its management in order to appreciate the interaction of the supply chain components. They seek to model the way supply chain operates as a system: "Supply chains are composed of components: people, organizations, technological structure, information flows, flows of physical good so, and flows of intangible services" [10]. The system includes interconnected parts that affect each other. This representation is very abstract and ignores explicitly consumers and suppliers. However, by studying how subsystems are interconnected, or which are the differences or the lack of articulation between subsystems, the feedback mechanisms or the interactions with the environment, the performance of supply chain system is approached. Henceforth, an approach in terms of open systems seems more appropriate to address the global supply chain. Liu [13] starts from the same postulate, arguing that the supply chain is a system of components. However, in order to represent it, he does not refer to the general systems theory but to the modern logistics supply chain theory. The purpose of this representation is to identify areas that may benefit from a reduction of logistics costs and increase efficiency and profits. This theoretical approach makes the link between management and logistics. The representation of supply chains takes ultimately the great ideas of the previous approaches.

The model presents the complex reality of the supply chain. To approach this complexity, Cooper et al. [14] and Lambert et al. [15] seek to capture both the complexity and reality by proposing a modeling of supply chain network with three structures: the type of supply chain partnership (primary and secondary partners), the structural dimensions of a supply chain network 
(horizontal and vertical structure), and the characteristics of process links among supply chain partners (managed process links, monitored process links, not managed process, and non-member process links). Garcia [4] and Garcia et al. [16] propose to use a modeling language or network presentation to build "a generic model of the supply chain which represents all the possible instances". In this way, some authors have focused on the interests of a representation of the supply chain by the social network analysis (SNA) [17-23]. The majority of these authors explain why theories from social networks are particularly relevant. They present the key elements that make up a network, indicators and usable analysis: nodes level (degree, closeness centrality and betweenness centrality) and network level (density, centrality, complexity). However, few of them go beyond in mapping a supply chain because they have recognized the difficulty of collecting network-level data in supply network (for a complete state of the art, see [23]).

Lazzarini et al. [17] demonstrate the interest to mobilize a SNA by the fact that supply chain analysis suggests vertical interdependencies that require " $a$ systemic understanding of resource allocation and information flow between firms". The interpretation of supply chain by an SNA is interesting because "supply chains are not really linear chains but most often expansive networks", which explains the neologisms "supply networks" or "net chains" [17,20,23]. According to Carter et al. [19], SNA "can be applied both within and between organizations in a supply chain". SNA analyses the structure of a network and map the relation among a group of actors. The relations can represent linking, communication, service or products. SNA describes and analyses the interrelationships of units or nodes within a network. In fact, SNA contribute to maps the complexity of supply chain. Supply chain consists of several nodes, which can be call "actors". Each actor is a character, a link of the chain, a part played by a performer.

Our work follows this path, while trying to go further. Indeed, our goal here is to assess and map all levels of network modeling of the WSC, based on SNA [24-27]. According to Kim et al. [23], "the term of 'network' into supply chain management research represents a pressing need to view supply chains as a network for firms to gain improved performance, operational efficiencies, and ultimately sustainable competitiveness". Theories of social networks allow taking into account all the social interactions that may influence the choice of actors of the supply chain and supply chain as a whole, because each actor is not isolated but is part of a set of relationships, which influence their choices. Thus, we agree with Borgatti \& Li [21], who argue that "the ego network concept is probably the closest to a supply chain theorist's intuitive understanding of a supply network, but it is not a perfect match". We will refer to a "meso-social" level analysis, i.e. expanded to actors' relations. Three levels of analysis are to be considered for modeling the supply chain: the triad [28,29]; the group [21,30,31]; and the complete network $[29,30]$.
Regarding the triad, the analysis focuses on the relationship formed by three actors, interconnected within the structure in which they fit and with respect to all other network triads. Analysis cares about all the strategies underlined by the triads. Each actor can have a different broker role. Let us note that the dyad was not chosen because we consider here that a network starts with three players. Regarding the group, it is a set of actors who know each other and maintain privileged relations of same nature. The group is composed of relatively homogeneous actors who react similarly to the dissemination of standards, for example. They maintain relatively dense interlinks. Concerning the complete network, it's a network restricted by relevant socially instituted borders with an a priori internal network cohesion. Existing borders are those of the supply chain and relationships are dense.

\section{Modeling the WSC}

In general, research in logistics offers several possible analysis units such as individuals, functions, companies or organizations, sectors or industries, interfaces or relationships, chains where the emphasis is made on flows between companies or projects, processes or information systems [32]. The three levels of analysis for modeling WSC include the following items: triads, groups and complete network. Nodes are composed by several actors and ties are only "contractual relationship" of several types: purchase relationship (wine grape grower or producer and raw materials supplier, grape grower and producer sells wine grapes), contractual outsourcing relationship (freight forwarder), relationship selling, relationship norms (implementing the same standard quality). In our exploratory analysis, it is important to have only one unit of analysis to assess the three levels of WSC. The unit we have chosen is the "contractual relationship" allowing us to go beyond the mere supply network. Our model is a simplified representation of contractual relations between actors in a generic form that each country will have to take ownership. We seek to reflect the diversity of actors and not their number. Then, each actor is actually a community. The goal is a simplified representation, a global multi-dimensional and coherent view. For a detailed presentation of the actors, see Table 1 below, adapted from $[4,16,33]$ and the authors of this paper.

\subsection{The triad}

In a triad each central actor has a different role. Table 2 below provides an illustration of different possible roles. Being inserted into a network facilitates the solution of problems and reduces costs (transaction, coordination, opportunity, etc.). For example, adhering to standard GS1 allows each actor in the supply chain to be connected to the upstream and downstream actors by a following up of standard. The GS1 system of numbering and bar coding applies all along the WSC: from the grape grower to the retailer, to facilitate traceability. As an illustration, the grape grower is responsible for the production. Each plot or block of vines is identified with Global 
Table 1. Actors of supply chain: companies with different functions.

\begin{tabular}{|c|c|}
\hline Actors & Definitions \\
\hline Raw material supplier & $\begin{array}{l}\text { This actor provides wine producers and fillers/Packers with all the supplies needed for wine-making } \\
\text { or filling and packing. The main activities are: receive new orders from wineries and/or fillers/packers, } \\
\text { prepare orders, send supplies to the wineries and fillers/packers, store supplies, etc. }\end{array}$ \\
\hline Grape grower & $\begin{array}{l}\text { The grape grower is responsible for the production and harvest of the grapes. The main activities of grape } \\
\text { growers are: planting the grapes, cultivating and pruning the vines, eliminating the inadequate vineyards, } \\
\text { fertilizing the vineyards, controlling plagues, harvesting grapes, etc. }\end{array}$ \\
\hline Wine producer & $\begin{array}{l}\text { Wine producers are responsible for receiving grapes, the elaboration, manufacture and/or blending of } \\
\text { wine products. In general, the main activities to elaborate wine are: receiving and weighing the grapes, } \\
\text { crushing,stemming and pressing juice, addition of sulfite and decanting, addition of yeast, fermentation, } \\
\text { refrigeration, clarification and stabilization, temperature control, preparation for bottling, maturation in } \\
\text { bottle, etc. }\end{array}$ \\
\hline Cooperative winery & $\begin{array}{l}\text { A group of grape producers join their resources to own a winery at a lower cost per unit by maximizing } \\
\text { the production volume. Grape producers bring their grape at the winery cooperative which commercializes } \\
\text { their wines to numerous customers: trader, restaurateur, retailer and mass market distribution industry. }\end{array}$ \\
\hline Bulk wine distributor & $\begin{array}{l}\text { The bulk distributor is responsible for reception, storage, dispatch, processing, sampling and analysis of } \\
\text { bulk wine. The bulk distributor receives bulk wine from the wine producer. The wine is usually pumped } \\
\text { into transport containers such as road tankers or barrels. When the wine arrives at the "tank farm", the } \\
\text { bulk distributor checks the receiving documents and takes samples for tasting and analysis. He approves } \\
\text { or rejects the wine (if rejected, the wine returns to the nominated source). }\end{array}$ \\
\hline Transit cellar & $\begin{array}{l}\text { The transit cellar is responsible for the reception, storage, dispatch, processing, sampling and analysis of } \\
\text { bulk wine. The transit cellar can be part of the filler/packer company (geographically separated or not) } \\
\text { or can be outsourced. The transit cellar receives bulk wine from bulk distributors in different kinds of } \\
\text { containers. During the transit cellar stage, the wine is prepared for onward sale and filling. It is loaded for } \\
\text { transit to the customer and is accompanied by all the appropriate documents. }\end{array}$ \\
\hline Filler/packer & $\begin{array}{l}\text { Fillers/packers are responsible for reception, analysis, filling, packing and dispatch of finished goods. The } \\
\text { filler/packer receives containers of bulk wine from the wine producer, and then the wine is filled into } \\
\text { different kinds of packages. Consumer units, such as bottles, bag-in-box, tetra packs, etc. are produced } \\
\text { from the wine batches supplied. }\end{array}$ \\
\hline Freight forwarder & $\begin{array}{l}\text { This actor organizes the shipment planning, which is the process of choosing shipment frequencies and } \\
\text { deciding for each shipment which orders should be assigned. It also includes the safe and efficient } \\
\text { movement of goods on behalf of an exporter, importer or another company or person, sometimes including } \\
\text { dealing with packing and storage. Typical activities include: researching and planning the most appropriate } \\
\text { route for a shipment (taking into account the nature of the goods, cost, transit time and security), arranging } \\
\text { appropriate packing (taking into account climate, terrain, weight, nature of goods and cost) and delivering } \\
\text { or warehousing of goods at their final destination. }\end{array}$ \\
\hline Freight operator & $\begin{array}{l}\text { They supply service for transporting goods from the winery to the importer or to other actors (distributor, } \\
\text { wholesaler, retailer, etc.), by air, through airline services, by sea through shipping lines or by road and rail } \\
\text { through different operators. The courier could be an express/parcel carrier trucking company, an ocean } \\
\text { liner, a railroad or an air carrier/integrator. }\end{array}$ \\
\hline Importer & $\begin{array}{l}\text { This actor buys goods from the wine producer and is responsible for the reception, storage, inventory } \\
\text { management and dispatch of finished goods, which receives from the freight forwarder through the freight } \\
\text { operator. The importer sales and delivers finished goods to the wholesaler or distributor of the destination } \\
\text { country depending on the distribution channel used in the country. }\end{array}$ \\
\hline $\begin{array}{l}\text { Finished goods distrib- } \\
\text { utor }\end{array}$ & $\begin{array}{l}\text { This actor is responsible for the reception, storage, inventory management and dispatch of finished goods, } \\
\text { as well as re-packing and re-labeling as per specific customer requirements required. }\end{array}$ \\
\hline Wholesaler & $\begin{array}{l}\text { The wholesaler receives pallets and cartons from the finished goods distributor and picks and dispatches } \\
\text { goods to the retails stores. They put new orders to the finished goods distributor, to the importer and may } \\
\text { also buy directly from the winery. }\end{array}$ \\
\hline Retailer & $\begin{array}{l}\text { The retailer receives finished goods from the finished goods distributor or the wholesaler depending on the } \\
\text { distribution channel. The retailer sells consumer units (bottles, cartons) to the end consumer. The different } \\
\text { sales' channels are: hyper/supermarket, liquor stores, drugs stores, specialist store, hotels, restaurants, } \\
\text { catering, clubs, etc. }\end{array}$ \\
\hline End consumer & $\begin{array}{l}\text { End consumers may buy finished goods directly from some wineries, or they can make an indirect order } \\
\text { of new products when they go to the store and chose some kinds of wine. }\end{array}$ \\
\hline
\end{tabular}


Table 2. Roles of central actors.

\begin{tabular}{|c|c|}
\hline Triad & $\begin{array}{c}\text { Example of role } \\
\text { for the central actor in the triad }\end{array}$ \\
\hline Freight Operator - Importer - End consumer & $\begin{array}{c}\text { Intermediate } \\
\text { To turn them into its own advantage, dealings } \\
\text { between networks members }\end{array}$ \\
\hline $\begin{array}{c}\text { Breight Forwarder }- \text { Freight operator } \\
- \text { Importer }\end{array}$ & $\begin{array}{c}\text { Coordinator } \\
\text { To facilitate or control the flow }\end{array}$ \\
\hline $\begin{array}{c}\text { Filler/packer }- \text { Finished goods distributor } \\
- \text { Wholesaler }\end{array}$ & $\begin{array}{c}\text { To reconcile several options of network } \\
\text { members and align goals }\end{array}$ \\
\hline $\begin{array}{c}\text { Wholesaler }- \text { Retailer }- \text { End consumer } \\
\text { To distribue ressource }\end{array}$ \\
\hline $\begin{array}{c}\text { Hub } \\
\text { Transit }- \text { Filler/packer }- \text { Finished goods } \\
\text { distributor }\end{array}$ & $\begin{array}{c}\text { To facilitate or control the flows of supply } \\
\text { across the whole network }\end{array}$ \\
\hline
\end{tabular}

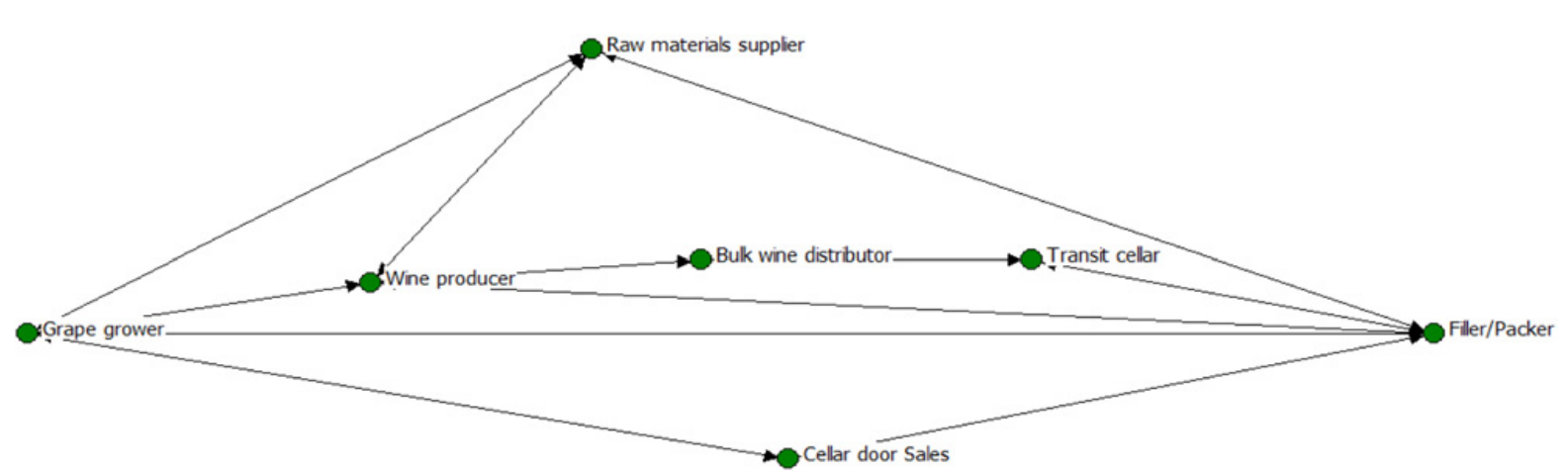

Figure 1. Production group.

Note: Arrows on all figures of this paper symbolize the chosen unit of analysis, i.e. the "contractual relationship".

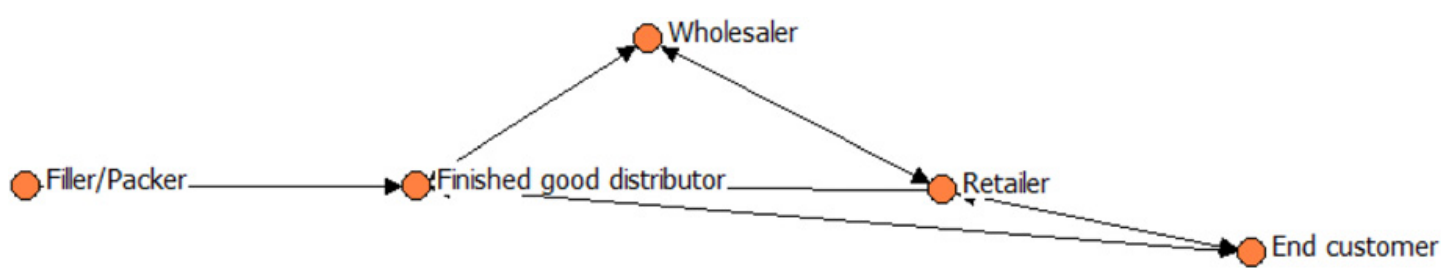

Figure 2. Distribution on national market.

Location Number (GLN), which is allocated by the grape grower. After the transformation from juice to wine, the wine producer adds to GLN identification, a product identification (GTIN), a shipping container identification (SSCC) and the quantity of wine dispatched (AI). When the bulk distributor received the wine, he adds a new identification, and so forth. Normative social relationships help bringing favorable factors to the firms performance (in terms of trust, traceability and information transfer), which are not found in the adjustment by the market.

\subsection{The groups}

It brings together actors who maintain relatively dense interlinks, because they are linked in a production chain, processing or services. In the WSC, there are three groups which have functioning, rules and strategies both specific but linked within a complete network: the production group, the distribution on "national market" and the distribution on "international market". The production group includes the following actors [4,34]: the grape grower, the wine producer, the bulk wine distributor, the transit cellar and the filler/packer (see Fig. 1). Upstream group also maintains relations with the raw materials supplier and downstream with cellar door sales. However, this group is not the same, nor as complete in all countries. There are several possibilities based either on dyads (wine producer-filler, grape grower-packer) or triads (grape grower-wine producer-filler/packer).

According to Garcia [4], "from the point of view of the relationship between order arrival and production release, production systems can be classified into make to stock/by to stock or make to order/buy to order (...). And for the packing several solutions: bottle to order, label to order, pack to order, deliver to order". The distribution on national market includes the following actors $[5,16,33]$ : the finished goods distributor, the wholesaler and the retailer (see Fig. 2). Upstream the group also maintains relations with the filler/packer and downstream with the end consumer. 


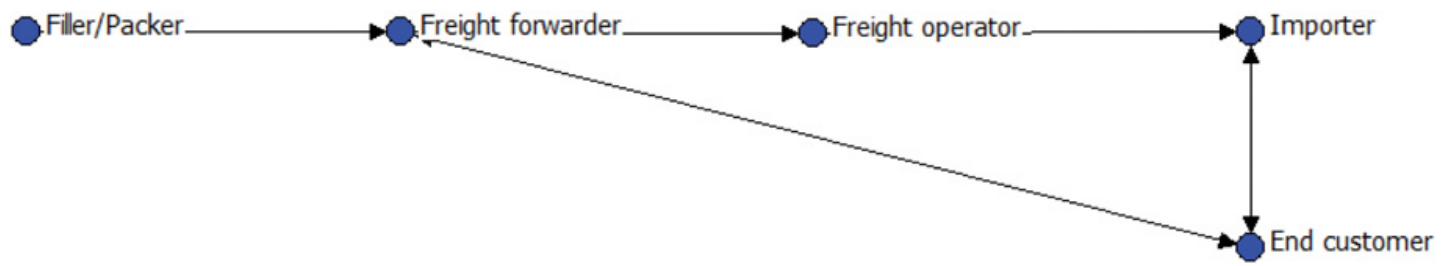

Figure 3. Distribution on international market.

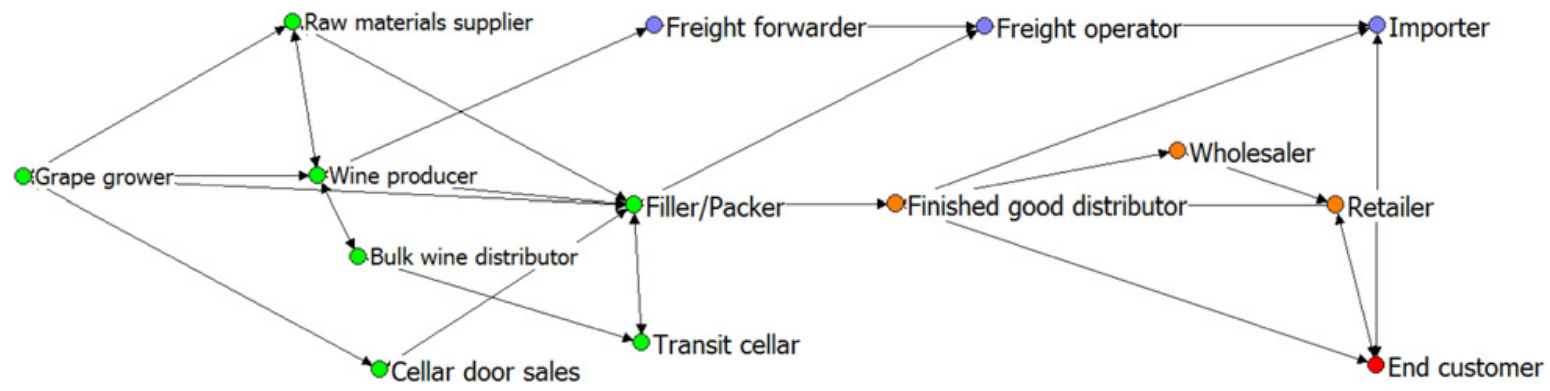

Figure 4. Complete network.

This modeling of the distribution group on the national market is having variations between countries that range from the dyad (distributor-end consumer or retailer-end consumer or wholesaler-end consumer or cellar door sales-end consumer) to the triad (distributor-retailerend consumer or distributor-wholesaler-end consumer or wholesaler-retailer-end consumer). The distribution on international market includes the following actors $[5,16]$ : the freight forwarder, the freight operator and the importer (see Fig. 3). Upstream the group also maintains relations with the filler/packer and downstream with the end consumer.

In case of wines distributed on the international market, the wine is distributed through the importer. Several variants are possible, for example, the freight forwarder may be conventional freight forwarder or LSP. In all cases all are match-makers. The importer buys wine from different wineries and sells it using the system with three levels of service, which is composed of finished goods distributor, wholesaler and retailer. The producer uses the service to coordinate freight shipping. Forwarder, in turn, uses the services of a freight operator for wine shipping. The match-makers do not trade. They relate both buyers and sellers. They are recruited to facilitate the transaction when the cost of information search and transaction is too high for partners. These intermediaries (middlemen) through their network allow reducing costs. Freight forwarder may be conventional or market-makers forwarders. In the latter case market-makers buy and/or sell for their own account (from selling price and offer price they set call).

\subsection{Complete network}

It is a network that expresses itself in terms of: nodes representing the different actors of the WSC, contractual relationship constituting our unit analysis and trust coordination links and norms. Strong ties are representative of local integration, while weak ties provide the overall network integration. The morphology of this network expresses structure contextual relations, inseparable of the strategic behavior of each actor and the role of each individual within this structure. The role is thus a complex construct that is similar to the concept of status. Thus, the filler/packer can be seen as a "bridge" between the three groups. It is a point of passage between two groups who are or have themselves access to different resources. Burt [35] has shown that this position of "intermediary" can bring to the concerned party two types of profits or profit opportunities. The benefits of control, on the one hand, which runs between two groups of contacts and benefits in information and communication, on the other hand.

\section{Integrating conventional LSP in the modeling}

Fulconis et al. [36] give a general but adequate definition of the LSP: "A firm ensuring the performance of logistical activities on behalf of a manufacturer or a large retailer". But there immediately follows three LSP families, depending on the complexity of their service offer, not on their strategic position in supply chains: (1) conventional LSP, simply executing physical operations related to transport, handling and storage of customers' work-in-process components or finished goods along a supply chain; (2) value-added LSP, who additionally include the management of manufacturing operations (e.g. some form postponement activities), administrative operations (e.g. invoicing) and information operations (e.g. tracing and tracking); and (3) dematerialized LSP, who own almost no physical resources, but build a customized service offer for their customers by involving the resources from different partners.

If the first and second families are conventionally called third party logistics (3PL), the third family belongs to the fourth party logistics (4PL), whose job is to design and sell integrated supply chain solutions by coordinating activities performed by hauliers, storage operators, subcontractors, packaging companies, etc. In this case, each 
supply chain solution is adapted to the needs of one customer, knowing that 4PL sell several supply chain solutions at the same time to a customer portfolio, from standard modules. The 4PL main trade is to assemble logistical modules that tightly linked with one another, form a customized package deal of services. From this point of view, 4PL clearly develop a modularity strategy, in Schilling's sense [37]: "Modularity is a general systems concept: it is a continuum describing the degree to which a system's components can be separated and recombined, and it refers both to the tightness of coupling between components and the degree to which the "rules" of the system architecture enable (or prohibit) the mixing and matching of components".

\subsection{The rise of value-added logistical services}

With a historical perspective, manufacturers have been long-standing adepts of own account logistics. In the 1920 s, they manifest the will to organize their business structure by abandoning wholesalers and independent traders, accused of hindering the implementation of an active sales policy. Examining the cases of bottled mineral water in France, Marty [38] underlines how wholesalers were to remain present until the 1960s, before disposable packaging (without consignment) was massively adopted by manufacturers. The rationalization of logistics would not be on the manufacturers' agenda before many decades, but the ownership of regional warehouses, although having narrow market coverage, allowed them to reach small retailers without colliding with the intermediaries. In other words, the well of manufacturers was to control the supply chain to accompany their marketing strategy in gaining control over clients.

On their side, and nearly at the same moment, a few large French retailers like Casino and regional cooperatives understand the interest of integrating the wholesale function. The significant increase of capacities of goods storage (and consequently of purchase) shows the possibility to increase the negotiation power vis-à-vis the manufacturers by buying directly from their factories. Here again, the option chosen is the own account logistics, for lack of a relatively efficient rental storage offer. The trend reverses during the 1970s, in the UK initially. Indeed, numerous large British retailers having taken control of the wholesale function start to turn to LSP to ensure the entire tasks linked to store purchasing. We can identify Exel Logistics as being the first modern LSP, following a partnership operation with Marks \& Spencer in the middle of the 1970s.

Then, the outsourcing logistics movement spreads out progressively to France. The main beneficiaries are powerful road transport companies that have grown their offer and, at a lesser extent, dynamic warehouses [36]. Indeed, these operators understood rapidly that the phenomenon of outsourcing logistics was part of a largescale movement, that is to say the specialization of clients in their core competences and their correlative research for external skills in terms of physical distribution. For the more dynamic road transporters, the diversification towards high added value logistics services allows to shift the bargaining with the clients on non-price dimensions, for example the quality and reliability of services related to the actual transport of the products, thus by avoiding a part of the extremely costly hyper-competition process that are common in simple transport activities.

Having for ambition to give a synthetic view of the logistics industry in Europe, partly cleared from national specificity, Cooper et al. [39] chose to integrate the client's choice in their analysis; their work is still an authority twenty years later. The central ideas of the authors are to build a strategic matrix based on the client's degree of implication in the production process of the logistical service. According to Cooper et al. [39], any logistical service can therefore be studied starting with two distinct levels. The first level, managerial and strategic, shows the task sharing between the supplier (LSP) and the user (client) of the service. In other words, defining who will organise the supply chain, who controls the original concept and who organizes the various logistical operations, whether we speak of transport or of a broader offer associating activities on a modular platform. The second level, capacitary and contractual, indicates if the logistical services are dedicated to a single client, if they concern a small number of clients with the same need or, finally, if they aim at a large number of users with no specific expectation. That is, knowing under what conditions the different logistical capacities can - or cannot - be shared. The mixing of these two levels results in the border marking of the work of LSP based on a series of contracts: customer dedicated, shared user or common user.

For the last ten years, much academic literature in marketing, SCM and strategic management has attempted to define the limits (or borders) of the third-party logistics industry with reference to operations performed by LSP - more or less complex depending on the nature of outsourcing contracts [36]. It is obviously impossible to sum up their contributions and limits here. We will simply mention a recent survey conducted in France by the Observatoire de la Prestation Logistique, the interest of which is to divide service offer into three distinct parts: a first feature called "Core business", a second feature called "Additional customer services" and a third feature called "New professions" [40]. Table 3 lists the various technical items making up each feature. It is evident that some operations, such as the management of a call center or co-manufacturing, have a link with what is traditionally meant as belonging to logistical services.

For example, co-manufacturing corresponds to a mass customization policy, conceptualized by Pine III [41], in which the LSP receives, on behalf of a manufacturer, a set of components. Their final assembly will be realized depending on the large retailers' orders. The expertise required here is of a manufacturing nature, not only logistical. The more advanced sectors include mobile telecoms, information systems, household appliances, etc. The paper will later go back to this type of value-added services with reference to the implementation of modular systems. But let us note, as Roques \& Michrafy [40] did, that French LSP are not always convinced they currently have the required know-how to perform mass customization operations, but the majority thinks that they 
Table 3. Logistical service offer: the three dimensions.

\begin{tabular}{|l|l|l|}
\hline (1) Core business & (2) Additional customer services & (3) New professions \\
\hline - Order preparation & - After sales service & - Site installation \\
- Stocking/storage & - Customer billing & - Co-manufacturing \\
- Inventory management & - Archiving & - Wrapping \\
- Transport & - Shelf display & - Managing a call center \\
& - Storage on behalf of customers & - Co-packing \\
& & - Boxing \\
& & - Information technologies \\
\hline
\end{tabular}

Source: Adapted from [40].

will acquire it in the next few years, as a key expertise of logistical management. The French situation is far from being isolated and unrepresentative of the global trend. Many LSP in Northern Europe, in the USA and Asia reason in the same way, and are planning a significant widening of their service offer. Originally focused on transport and warehousing activities, it is now focused on the management of numerous and complex interfaces with their customers from the manufacturing and retailing sectors. Lai [42] conducted a survey of LSP in HongKong, to assess their service capabilities in two types of logistical services, in complement to conventional freight forwarding service (FFD):

- Value-added logistical services (VAL): assembling, packaging \& labeling, purchasing \& procurement, cross-docking, customer-specific label printing, warehousing, etc.;

- Technology-enabled logistical services (TEL): information systems management, tracking and tracing, web-based linkages, receiving and sending shipment notices, etc.

The field study concluded, from a cluster analysis, that there were four types of LSP, with $27.1 \%$ labeled as "Full service providers", because their level of capability is high in each logistical service (FFD, VAL and TEL). The study also emphasizes the presence of an unusual group of LSP, called "Nichers", who as a priority have developed capabilities in the value-added and technology-enabled logistical services (VAL and TEL), to the detriment of conventional freight forward service (FFD). Finally, LSP centered on basic transport operations now only account for a quarter of the sector. The large number of LSP who have developed new value-added services, as shown in Lai's field study [42], shows the magnitude of logistical mutations in some South-Eastern Asian countries that are probably occurring at a greater speed than in Northern Europe. This type of mutation is not due to chance. It simply corresponds to the fact that LSP have known how to progressively widen their service offer to answer the expectations of manufacturers and large retailers who have also progressively abandoned many logistical activities to better dedicate themselves to the management of their core business.

\subsection{LSP in the WSC: A cultural adaptation}

At last, what role can be played by the PSL in the present changing context of WSC? The French case is interesting. It represents an avant-garde tendency that other countries could watch closely. French large retailers occupy an ever more prominent place in wine commercialization, including some of superior quality. Thus, it is not unusual to buy renowned Champagne or a Grand Cru of Bordeaux in a grocery store, in a hypermarket or in a convenience store. Undoubtedly, superior quality wines have become more accessible, and their logistics is comparable to that of convenience goods. The LSP have built their expertise and their legitimacy from 1980 by working for large retailers, and taking over highly developed additional customer services. The LSP key factors of success were to organize higher volume flow of a kind never experienced before.

Looking at sources of competitive advantage deployed by LSP since their emergence, and to their expansion as a result of expanding their expertise area, it is possible to identify several meaningful elements that further invite to consider their ability to rapidly integrate the WSC. These meaningful elements provides references to existing dimensions considered as "cultural", referring to the culture as the way of thinking a formalized action, acquired and shared by a plurality of individuals and/or organizations, that constitute in fine the fundamentals of a community with overall coherent behaviors [43]. The relevant dimensions are as follow:

- LSP own a historical culture of products routing towards hypermarkets, supermarkets and convenience store; it is the "core" of their business model. The main idea is to consider the pooling of products as a system allowing important economies of scale and scope. The centralized hypermarket and supermarket procurement system, established in the early 1980s [39], is based on shared warehouses and platforms for a number of retailers. LSP have learned very early to associate heterogeneous products, including for competitors, by underlining the importance of standardization to reduce the retail shop unit procurement cost.

- LSP have a technical cultural of routing products towards hypermarkets, supermarkets and convenience store; they know how to develop management tools and techniques facilitating aggregation of flows, thanks to their capacity to standardize the management of interfaces for a multiplicity of supply chains. The WSC can easily be associated to other food supply chains. This is obviously the case of infrastructures provided as a part of shared contracts, but the same logic could be applied to dedicated contracts. For those, technological learning phenomena exist. It could be duplicated from one supply chain to another as a 
specific investment made for a customer outside the WSC, for example relating to picking orders, and lead to assimilate a know-how potentially adapted to current or future customer inside the WSC.

- LSP have a communication culture of routing products towards hypermarkets, supermarkets and convenience store; they know how to memorize their different experiences, both in tacit knowledge and explicit knowledge, to apply ready-made solution in a widerange of answers provided to various customers. As Cézanne \& Saglietto [44], we can speak of knowledge capitalization acquired from different contracts completion. Building a supply chain ondemand is based on modules arrangement (and/or competences) in which versatility is an important attribute. The most modernist LSP, specifically the 4PL, have in their organizational memory a variety of modules combinations, in which interfacing is easily adjustable depending on new demands to satisfy.

- Finally, LSP have a social culture of routing products towards hypermarkets, supermarkets and convenience store; they are embedded in numerous social (relational) networks by their activities bringing them at the interconnection of several business sectors, product families, value chains, etc. Regular contacts are tied at the decision-maker level, learning to know each other, developing positive affects, even empathies, favorable to the establishment of sustainable partnerships. The human part relative to collaborative supply chains success is an important research topic nowadays $[21,22,45]$. WSC history points out the importance of strong personal relation between individuals from a same region, a same terroir. This culture of direct interaction is conducive to the LSP, specifically in the case of 4PL [46].

In other words, all the evidence suggests that innovative LSP are able to remove without difficulty obstacles to market access, as they learn to do it in an emerging way, and more and more deliberate over time, for other supply chains in which they were present at the beginning (for example, pharmaceutical distribution). By the way, using LSP for WSC members represents without any doubt an effective reply to face the predominant position of some bulk wine distributors. Economic conditions, but also environmental pressures, are therefore extremely favorable to the development of LSP in the French WSC. It is an open question whether these actors will be qualified, in contractual terms, to exploit this competitive advantage and, above all, if they will have a sufficiently adaptive know-how to manage specific constraints relative to quality wines, in terms of products conservation for instance. Otherwise, there will be a risk of seeing new dynamic players, or historical operators as freight operators or wholesalers, monopolize the business.

\section{Discussion and conclusion}

The modeling exercise of the WSC offers two interesting conclusion. Firstly, it improves the understanding of the flow structure between the different supply chain members, how they are organized and what are the possible enhancement sources in their organization. Secondly, this exercise of modeling the WSC enable each of supply chain members to know is position on the WSC, the central role played by actors sometimes physically far from him, and after all to identify which actor can be considered (or not) as a node in the WSC. It is necessary to go beyond a cartographic representation of flows, as it may often be found in specialized research on supply chains optimization [47]. Indeed, the cartographic representation may not be sufficient to study dynamic evolution of supply chains, especially with the old flow organization destabilized by new competitors.

However, these new competitors are central in supply chains reconfiguration. That is why we investigated how LSP could durably transform the WSC using the European experience, in particular the French one, on logistics industry development since the 1980s. The increasingly variety of LSP skills in terms of flow monitoring are undeniable [36]. Accordingly, we have to consider their entrance in the WSC as ineluctable in the near future. In fact, this is already happening with the Bordeaux Wine Logistic, a dynamic French LSP proposing to Medoc owners, where there is one of famous Bordeaux wines, a warehouse being able to store 6 million bottles a year. The LSP ensure on his logistical platform the whole supply chain services, from the bottles receiving to the palletizing before shipping, including picking order and labeling bottle [48]. Several weak signals may confirm we are on the eve of a revolution in the WSC structuration. However, the arrival of powerful LSP raises several questions and it is imperative, to answer them, to build a research agenda as robust as possible. In our opinion, three thematic need to be investigated in priority:

- The LSP entrance fundamentally transforms the intermediation boundary on a transactional and logistical level. For many years, these two dimensions have been associated and it could have been relevant that finished goods distributor develops expertize in trading and in supply chain management. There no process to ensure it will be the case in near future. A strict tasks division will have to be considered to increase the trading activities and logistic activities performances. Other food supply chains have known such evolution, especially the packaged convenience goods, and, as a result, have seen the failure of intermediaries who decided to remain adaptable. In France, food wholesalers working with retailing industry could be used as example of those who failed to take the specialization turn on logistics competences.

- Obviously, the LSP entry will probably lead threatened competitors to conduct strategies of resistance. These strategies of resistance will be passive, by trying to protect as long as possible competitive positions on market niches; sometimes these will be active, by trying to affect and then to supplant LSP by pointing a lack of expertise on WSC products requiring processing and specific equipment, as hygrometric and atmospheric system control to avoid bacteria multiplication for example. Poirel [49] indicates on these researches relative to the strategies of resistance 
in the cultural industries that they could be successful if the environmental conditions, especially the end consumer expectations, are really supportive. In other words, a successful strategy of resistance by some competitors of the WSC could not be solely based on questioning the logistics services quality proposed by LSP.

- Therefore, it leads to explore a last thematic related to organizational issues and linked to the LSP capacity to become integrated into communities of practice established over decades. Thus, in France, the Grand Crus commercialization depends on a slimmed-down collective of individuals located on a confined territory. They know each other, like each other or hate each other, but in the respect of implicit conventions. Strictly speaking, we are in a very small world where intruders are sometimes not welcome. Community of practice, in this case, is built on a common value system and belief, a human ecosystem where individual concerns face the requirements of dominant collective strategies. It would be also possible to mention the Champagne [50], or the Sancerre [51], but the reasoning could be applied to many other territories. Nevertheless, there is some uncertainty about the capacity of LSP to penetrate easily these human ecosystems, mostly if they appear completely separated from territory. If the LSP unquestionably have a multiple dimensions culture enabling to consider their assimilation in the WSC, it is a vital condition that may not be sufficient to ensure their development.

This work is supported by cooperation program ECOSsud/MINCyT that provided the initial framework for the collaboration between the University of Nice Sophia-Antipolis, GREDEG CNRS, Nice, France, and the Universidad Nacional de Cuyo, Mendoza, Argentina (Project Code No. A13H02).

\section{References}

[1] A. Mariani, E. Pomarici, V. Boatto, The international wine trade: Recent trends and critical issues, Wine Economics \& Policy, 1(1), 24-40 (2012)

[2] M. Demossier, Beyond terroir: Territorial construction, hegemonic discourses, and French wine culture, Journal of the Royal Anthropological Institute, 17(4), 685-705 (2011)

[3] M. Fernandez-Olmos, J. Rosell-Martínez, M.A. Espitia-Escuer, Vertical integration in the wine industry: A transaction costs analysis on the Rioja DOCa, Agribusiness, 25(2), 231-250 (2009)

[4] F. Garcia, Modelado y medición de performance logística en la industria del vino (Unpublished Master Thesis, Universidad National de Cyuo, Mendoza, 2009)

[5] H. Min, G. Zhou, Supply chain modeling: Past, present and future, Computers \& Industrial Engineering, 43(1), 231-249 (2002)

[6] W. Stevenson, Production/operations management (McGraw-Hill, Boston, MA, 1999)

[7] Supply Chain Council, http://www.supplychain.org/ (2002), retrieved May 26, 2014
[8] R. Handfield, E. Nichols, Introduction to supply chain management (Prentice-Hall, Upper Saddle River, NJ, 1999)

[9] I. Chen, A. Paulraj, Towards a theory of supply chain management: The constructs and measurements, Journal of Operations Management, 22(2), 119-150 (2004)

[10] I. Caddy, I., M. Helou, Supply chain and supply chain management: Towards a theoretical foundation, Proceedings of the Second International Conference on Managing Enterprises (Newcastle, 1999).

[11] I. Caddy, M. Helou, Supply chains and their management: Application of general systems theory, Journal of Retailing \& Consumer Services, 14(5), 319-327 (2007)

[12] L. Von Bertalanffy, General system theory (George Braziller, New York, 1968)

[13] L. Liu, Research on the management system of enterprises using modern logistics supply chain theory, Procedia Engineering, 24, 721-725 (2011)

[14] M. Cooper, D. Lambert, J. Pagh, Supply chain management: More than a new name for logistics, International Journal of Logistics Management, 8(1), 1-14 (1997)

[15] D. Lambert, M. Cooper, J. Pagh, Supply chain management: Implementation issues and research opportunities, International Journal of Logistics Management, 9(2), 1-20 (1998)

[16] F. Garcia, M. Marchetta, M. Camargo, L. Morel, R. Forradellas, A framework for measuring logistics performance in the wine industry, International Journal of Production Economics, 135(1), 284-298 (2012)

[17] S. Lazzarini, F. Chaddad, M. Cook, Integrating supply chain and network analyses: The study of net chains, Journal on Chain \& Network Science, 1(1), 7-22 (2001)

[18] L. Ellram, W. Tate, C. Carter, Product-process-supply chain: An integrative approach to three-dimensional concurrent engineering, International Journal of Physical Distribution \& Logistics Management, 37(4), 305-330 (2006)

[19] C. Carter, L. Ellram, W. Tate, The use of social network analysis in logistics research, Journal of Business Logistics, 28(1), 137-168 (2007)

[20] R. Mueller, D. Buergelt, L. Seidel-Lass, Supply chains and social network analysis, Proceedings of the $2^{\text {nd }}$ International European Forum on Innovation and System Dynamics in Food Networks (Innsbruck, 2008)

[21] S. Borgatti, X. Li, On social network analysis in a supply chain context, Journal of Supply Chain Management, 45(2), 5-22 (2009)

[22] J. Galaskiewicz, Studying supply chains from a social network perspective, Journal of Supply Chain Management, 47(1), 4-8 (2011)

[23] Y. Kim, T.-Y. Choi, T. Yan, K. Dooley, Structural investigation of supply networks: A social network analysis approach, Journal of Operations Management, 29(3), 194-211 (2011)

[24] M. Granovetter, Economic action and social structure: The problem of embeddedness, American Journal of Sociology, 91(3), 481-510 (1985) 
[25] S. Wasserman, Social network analysis: Methods and applications (Cambridge University Press, New York, 1994)

[26] W. De Nooy, A. Mrvar, V. Batagelj, Eds., Exploratory social network analysis with Pajek, (Cambridge University Press, New York, 2005)

[27] D. Knoke, S. Yang, Social network analysis (Sage, Thousand Oaks, 2008)

[28] T. Snijders, The statistical evaluation of social network dynamics, Sociological Methodology, 31(1), 361-395 (2001)

[29] T. Opsahl, Triadic closure in two-mode networks: Redefining the global and local clustering coefficients, Social Networks, 35(2), 159-167 (2013)

[30] M. Newman, J. Park, Why social networks are different from other types of networks, Physical Review E, 68(3), 036122 (2003)

[31] B. Balasundaram, S. Butenko, I. Hicks, Clique relaxations in social network analysis: The maximum k-plex problem, Operations Research, 59(1), 133142 (2011)

[32] N. Fabbe-Costes, F. Fulconis, M. KoulikoffSouviron, La recherche en management logistique: la question des unités d'analyse et du périmètre, in N. Fabbe-Costes, G. Paché (Eds.), La logistique: une approche innovante des organisations (Presses Universitaires de Provence, Aix-en-Provence, 2013)

[33] GS1, Wine supply chain traceability: GS1 application guideline, http://www.GS1.org/ (2005), retrieved March 11, 2014

[34] I. Pretorius, P. Høj, Grape and wine biotechnology: Challenges, opportunities and potential benefits, Australian Journal of Grape \& Wine Research, 11(2), 83-108 (2005)

[35] R. Burt, Brokerage and closure: An introduction to social capital (Oxford University Press, New York, 2005)

[36] F. Fulconis, G. Paché, G. Roveillo, La prestation logistique: origines, enjeux et perspectives (Editions Management \& Société, Caen, 2011)

[37] M. Schilling, Toward a general modular systems theory and its application to interfirm product modularity, Academy of Management Review, 25(2), 312-334 (2000)

[38] N. Marty, L'eau embouteillée: Histoire de la construction d'un marché, Entreprises \& Histoire, 50, 86-99 (2008)
[39] J. Cooper, M. Browne, M. Peters, European logistics: Markets, management and strategy (Blackwell Publishers, Oxford, $2^{\text {nd }}$ ed., 1993)

[40] T. Roques, M. Michrafy, Logistics service providers in France-2002 survey: Actors' perceptions and changes in practice, Supply Chain Forum: An International Journal, 4(2), 34-52 (2003)

[41] J. Pine III, Mass customization: The new frontier in business competition (Harvard Business School Press, Boston, MA, 1993)

[42] K. Lai, Service capability and performance of logistics service providers, Transportation Research Part E, 40(5), 385-399 (2004)

[43] G. Rocher, Introduction à la sociologie générale. 1. L'action sociale (Editions du Seuil, Paris, 1970)

[44] C. Cézanne, L. Saglietto, Capital humain, prestataires de services logistiques et frontières de la firme, Revue d'Economie Industrielle, 135, 71-88 (2011)

[45] G. Paché, Coopetitive supply chains: Toward a social ties perspective, Management, 18(2), 125-140 (2013)

[46] N. Fattam, Le rôle des réseaux sociaux dans la construction d'une capacité de coordination au sein des chaînes logistiques: Le cas des 4PL (Unpublished doctoral dissertation, Aix-Marseille Université, 2014)

[47] M. Watson, S. Lewis, P. Cacioppi, J. Jayaraman, Supply chain network design: Applying optimization and analytics to the global supply chain (Pearson Education, Upper Saddle River, NJ, 2013)

[48] F. Fulconis, J. Nollet, G. Paché, La banalisation de l'offre de services logistiques: Quelles réponses stratégiques des PSL face au risque de l'effet "toboggan"?, Logistique \& Management (to be published)

[49] C. Poirel, Stratégies logistiques et stratégies de résistance dans les canaux de distribution, Logistique \& Management, 17(2), 65-73 (2009)

[50] J.-L. Barbier, Le modèle champenois, in S. Charters, V. Michaux (Eds.), Stratégies des territoires vitivinicoles: clusters, gouvernance et marque territoriale (Editions Management \& Société, Caen, 2014)

[51] V. Michaux, S. Charters, S. Jolly, Les facteurs clés de succès d'un système productif local entrepreneurial et d'un cluster en avance sur son temps: le Sancerre, in S. Charters, V. Michaux (Eds.), Stratégies des territoires vitivinicoles: clusters, gouvernance et marque territoriale (Editions Management \& Société, Caen, 2014) 